\title{
The Provision of Special Education in Zimbabwe: Realities, Issues and Challenges
}

\author{
Alfred C. Ncube (PhD), Lincoln Hlatywayo \\ Acting Pro-Vice Chancellor (Academic): Zimbabwe Open University \\ Senior Lecturer: Disability Studies and Special Needs Education, Zimbabwe Open University
}

\begin{abstract}
The research study explored the issues, realities and challenges regarding the provision of special needs education in Zimbabwe. Specific constructs studied were parental involvement, the nature and scope of the curricula and the general strengths of specialist teachers. The study was qualitative in nature though certain aspects of quantitative research were used such as the questionnaire and descriptive statistics. Respondents were drawn from 8 of the 10 provinces in Zimbabwe. They included 65 teachers, 40 school heads as well as 26 parents. Questionnaires were used as the primary data collection tool. The results show that parents are fairly involved in school activities. However, parents were mainly involved in administrative issues rather than in making decisions about the education of their children. While the curriculum for learners with disabilities was found to be satisfactory it lacked components that ensure the smooth transition of learners with disabilities into adulthood and employment. Lastly the study found that there are challenges faced in the recruitment of specialist teachers; shortage of trained teachers; refusal by trained teachers to teach special classes; centralized recruitment system; and poor incentives. The study recommends that all teachers colleges train teachers how to deal with children with disabilities and that a retention allowance be reintroduced for teachers of children with impairments. It is also recommended that parents of children with disabilities be empowered to actively participate in valued activities such as the design of Individual Education Programmes. Schools sign contracts with parents in which the later undertook to participate in all the outlined activities. Lastly the study recommended that there must be a clear cut transitional policy which specifies the paths to be followed by children with disabilities in school to enable them to move swiftly into adulthood and employment.
\end{abstract}

Key Words: Special Needs Education, Disabilities, Impairments, Inclusive Education, Curricula, Parental Involvement, Specialist Teachers

\section{Introduction}

The research study interrogated critical issues related to the provision of special needs education in Zimbabwe. In the rapid assessment of primary and secondary schools conducted by the National Education Advisory Board, Chakanyuka et al (2009) estimate that in Zimbabwe, as many as 469000 children may require special needs education. They further made the estimation that only $30 \%$ of these children were able to access special needs education by 1998. To think that this falls within the period when a figure of over $97 \%$ literacy rate was being quoted, the revelation invokes a sense of helplessness.

Viewed slightly differently, $70 \%$ of children with disabilities and other special educational needs were (or are arguably still being) denied their right to education. Of course, this situation in direct conflict with The Constitution of Zimbabwe, Article 2 of the United Nations Convention on the rights of the child (1989), the Convention on the Rights of Persons with Disabilities (2008), World Declaration for Education for All (1990), the UNESCO Salamanca Statement and Framework for Action (1994), and the Dakar Framework for Action (2000). Special Needs Education arrangements and provisions in Zimbabwe have, until recently, been planned with two main purposes in mind - either that special educational needs would be effectively diagnosed and cured or that children who presented particular special challenges would be taken out of circulation and placed in a special class or unit.

In many schools in Zimbabwe today such "solutions" are still in practice. In models such as these, problems often arise because many schools plan provision on the curing assumption or on the segregation assumption and only recently have many schools in Zimbabwe recognized the need for a combination of shortterm and long-term arrangements. Given the immediately foregoing, it becomes instructive to ensure that new legislation and current knowledge re-define the purpose of special needs education in ordinary schools and move towards inclusive education. As a result, it is no longer logical for an ordinary school to plan programmes to cure short-term difficulties while expecting long-term ones to be solved elsewhere. The study focused on these and other issues related to the provision of special education in Zimbabwe. 


\subsection{The Research Question}

The research study sought to answer the question

"What are the critical issues regarding the provision of special needs education in Zimbabwe"?

\subsubsection{Sub Research Questions}

In order to gain an in-depth insight of the main question the following three sub questions were developed

- To what extent are parents involved in the education of their children with disabilities?

- What is the nature and scope of the special education curricula used in schools?

- What is the general strengths of specialist teachers?

\subsection{Limitations}

While the study was not limited by some geographical boundaries not all provinces were covered. Matabeleland North and South Provinces were not included in the study mainly due to the distance involved in accessing the provinces which called for more resources. While this may have some effects on results generalisabilty the fact that all the other provinces were included countered the effects. In addition, it was very difficult for the researchers to reach out to many parents because these could not be found in one place like teachers and heads. As such, the parent sample was not representative enough to reflect the real views of parents with disabilities across the country. It has to be noted however that the parents were included in the study in order to triangulate views from teachers and heads who were the main respondents

\subsubsection{Parental Involvement}

\section{Literature Insights}

Schools and families share responsibilities for the socialization of the child. These common goals for the children with disabilities and other special needs are most achieved effectively when teachers and parents work together. According to this perspective, an overlap of responsibilities between teachers and parents is expected. Epstein (1987) also talks of the sequential perspective which stresses the critical stages of parents and teachers $\square$ contribution to child development. In this regard, parents teach needed skills to children until the time of their formal education around the ages of five or six. Then teachers assume the primary responsibility for children $\square$ s education.

Undoubtedly, these theoretical perspectives on home-school relations have a profound effect on parental involvement in the schools. According to Mpofu (2004), supported by Devlieger (1998), parents and guardians have little involvement in curricular and classroom practices beyond enrolling their children in schools where unplanned curricular are followed. Mpofu (1999) went further to postulate that in Zimbabwe there is a strong relationship between low economic status, low parental literacy levels and non involvement of parents in their children's education

\subsubsection{Nature and Scope of Curricula}

Students with disabilities in Zimbabwe are expected to go through one or more of the five types of curricula options available. Four of these were provided through the enaction of the Education Secretary $\square \mathrm{s}$ Policy Circular Number 36 of 1990.

These are:

Locational inclusion

Inclusion with partial withdrawal

Inclusion with clinical remedial instruction and

Unplanned or de facto inclusion

The fifth type of curriculum which seems practiced mainly in special schools is the school-based curriculum. According to Mkandla and Mataruse (2002) and Mpofu (2001), unplanned or de facto inclusion is the most common type followed in Zimbabwean schools. With this type of curriculum students with disabilities are exposed to the main curriculum of the regular school, in regular school settings. They are placed in these schools by their parents and guardians who seem to have very limited options. Mtepfa et al (2007) argued that the majority of such children, especially those with severe disabilities drop out of school before grade three. What then remains of the special education curriculum following a decade of educational decline?

\subsubsection{General Strengths of Specialist Teachers}

Chakanyuka et al (2009) make the observation that most teachers at special schools and special classes in Zimbabwe have no special training to teach learners with disabilities and other special educational needs. They attribute this situation to the general economic decline in the country within the past years, reaching a 
crescendo in the years 2007 and 2008. Mkandhla and Mataruse (2002) pointed out that the majority of schools in Zimbabwe lack the personnel and material resources to cater to a variety of significant learning needs. Cohen and Cohen (1986:294) note that "the majority of staff in mainstream schools have received no initial or inservice training for teaching pupils with special needs and may take on their new role with considerable trepidation."

\section{Methods}

The primary aim of the study was to establish the critical issues regarding to the provision of special needs education in Zimbabwe. The research was designed to be exploratory and descriptive and thus no attempts were made to establish causal relationships. As such the research method that guided the study was largely qualitative. However, elements of quantitative methods were employed in instrumentation and in data analysis where descriptive statistics were used. In the main, therefore, a descriptive survey design was used to collect data. The population included purposively selected special schools and schools with special classes, resource units, integrated classes and inclusive classes in Zimbabwe. Purposive sampling was preferred to ensure that the different special needs education arrangements and provisions were considered given the uneven distribution of special needs education facilities in the country. In this regard, efforts were made to cover all the types of disabilities in 8 of the 10 Zimbabwean education provinces. The representative sample was composed of forty school heads, sixty five specialist teachers and twenty six parents. Open-ended questionnaires and structured interviews were used to collect data. The researches made use of The Schools Psychological Services staff in all the 8 studied provinces. These distributed and collected back the questionnaires.

\subsubsection{Parental Involvement}

\section{Findings}

Table 4.1: The extent of the parents' participation in school activities $(n=26)$

\begin{tabular}{|c|c|c|c|}
\hline Questions for parents & Never & Rarely & Many times \\
\hline How often do you attend meetings at school? & 0 & 6 & 19 \\
\hline How often does your child's school contact you about his/her work? & 0 & 3 & 23 \\
\hline
\end{tabular}

As table 4.1 clearly shows, most parents were involved in school activities. Some parents of deaf children commented that they need more training in Sign language.

On the other hand it was clearly evident from the responses that both teacher and head respondents felt that schools, to great extent, involved parents in their activities. It is interesting to note, in general terms, that teacher respondents were more satisfied with the extent of parental involvement in school activities.

Table 4.2: Heads' estimation of parental involvement in selected school activities $(n=40)$

Table 4.2: Heads estimation of parental involvement in selected school activities (n=40)
\begin{tabular}{|l|c|c|}
\hline Activity & Nf & \%f \\
\hline Parents SDCs meetings & 40 & 100 \\
\hline Consultations days & 27 & 68 \\
\hline Discipline and counseling & 8 & 20 \\
\hline Community based rehabilitation & 5 & 13 \\
\hline Sporting activities & 19 & 48 \\
\hline Field/educational trips & 10 & 25 \\
\hline
\end{tabular}

The data in table 4.2 show that schools involve parents of children with disabilities mainly in management and administration issues such as meetings compared to the more child centred issues such as rehabilitation.

\subsubsection{Nature and Scope of Curricular}

This section, therefore, sought the views of the respondents on the types of curricula used in special needs education.

Table 4.3: Responses by Heads $(n=40)$ and teachers $n=65)$ on the question on the type of curriculum used in special needs education $(n=105)$

\begin{tabular}{|l|c|c|}
\hline Type of Curriculum & $\mathbf{n}$ & \%f \\
\hline Individualized & 57 & 54.2 \\
\hline General & 40 & 38 \\
\hline School-Based & 8 & 7,8 \\
\hline Total & $\mathbf{1 0 5}$ & $\mathbf{1 0 0}$ \\
\hline
\end{tabular}

From table 4.3, it is evident that many schools (mainly special schools) were using individualized curriculum to educate children with disabilities. A significant percentage $(40 \%)$ of the respondents also 
indicated that they were using general school curriculum. Schools were also designing their own curriculum for children with disabilities as shown by $8 \%$ of the respondents.

Table 4.4: Parents' evaluation of their children's curriculum suitability ( $n=26)$.

\begin{tabular}{|c|c|c|}
\hline Response & nf & \%f \\
\hline Yes & 16 & 61.5 \\
\hline No & 10 & 38.5 \\
\hline
\end{tabular}

It is evident from table 4.4 that the majority of parents were satisfied with the curriculum offered to their children $(61.5 \%)$. On the other hand, some parents (38.5\%) showed dissatisfaction with the curriculum offered to their children. Asked to comment further the majority of the parents who expressed satisfaction said the curriculum offered practical subjects. Below are some of the comments by parents who said the curriculum was not suitable:

Facilities at my child's school are inappropriate

Examinations written are not adapted to suit my child

Sign language does not consider technical terms and my child is academically affected at secondary school level.

Evaluation of curriculum comprehensiveness in preparing children with disabilities for adulthood and employment by Heads $(n=40)$ and teachers $(n=65)$

$61 \%$ of the respondents said No, $37 \%$ said Yes while it was not applicable to $2 \%$ of the respondents

From these results, it is clear that the majority of the teacher and head respondents felt that the curricula being followed in respect of the education of learners with disabilities and other special needs were not sufficient to prepare the learners for transition into adulthood and employment.

Respondents were further asked to comment on the ways in which the current curricula could be improved and the following ways were the most frequent:

$\square$ There was need to design more integrated curricula that take into account all transition aspects into consideration.

There was need to provide well-furnished teaching-learning facilities.

There was need to provide assistive devices to increase curricula access by learners with disabilities.

\subsubsection{Strengths of Specialist Teachers}

Responses by heads to the question whether school heads face problems in recruiting specialist teachers $(n=27)$

$67 \%$ said Yes while $33 \%$ said No.

As indicated, most school heads (67\%), especially those in ordinary schools, said they face problems in recruiting specialist teachers. The reasons for their difficulties are summarized in table 4.5.

Table 4.5: Reasons given by school heads for challenges faced in recruiting specialist teachers $(n=27)$

\begin{tabular}{|l|c|c|}
\hline Problem & Frequency & \% \\
\hline Shortage of trained teachers & 27 & 100 \\
\hline Trained teachers refuse to take special classes & 25 & 92.2 \\
\hline Centralized recruitment system & 18 & 66.6 \\
\hline Poor incentives & 17 & 63 \\
\hline
\end{tabular}

As is evident in table 4.5 , the respondents identified the following reasons as being the main challenges faced in the recruitment of specialist teachers; shortage of trained teachers; refusal by trained teachers to teach special classes; centralized recruitment system; and poor incentives.

\section{Discussion}

The research results have shown that parents are fairly involved in the education of their children. However it is sad to note that the majority of parents are happy with their level of involvement and yet the activities in which they are involved are mainly secondary. While it can not be disputed that parents are involved in meetings, sports and consultation days non of the respondents indicated some key functions of parents such as their membership to the construction and their supervision of Individual Educational Programs. Some parents contradicted themselves when they evaluated their involvements by schools as good and at the 
same time complain of failure to communicate with their children using sign language .This concurs with (Mpofu (2004),supported by Devlienger (1998) who said parents and guardians have little involvement in curricular and classroom practices beyond enrolling their children in schools where unplanned curricular are followed . In addition the absence of specific legislation which specify the functions of the school and parents is greatly militating against the involvement of various partners in the provision of special needs education

The results have shown that about half of the respondents who were mainly from special school said they were using individualized curriculum . This is in line with the provision of many international conventions such as the Salamanca Statement (1990) and the Jomtein Report (1994). However the $40 \%$ and $8 \%$ of the respondents said they were using the general school curricula and school based curricula respectively .These were mainly from the ordinary schools (mainstream). Also about $61,5 \%$ of the parents who were mainly from special schools said they were satisfied with their child $\square$ s curriculum while $38,5 \%$ said they were not satisfied .The later had their children enrolled in either special classes or resource units. Parents of children who are deaf said that the curriculum was not suitable as their children were forced to speak instead of being taught and examined in sign language .This means a lot to the education of deaf learners .Are we being fair when we teach them to speak, and make them being examined in English and have their exams marked by general school teachers as is the current trend? Surely a lot need to be done in this area and further research is recommended. A more interesting trend emanating from the curricula issue is that $61 \%$ of the respondents said that the curricula offered to children with disabilities was too general and not comprehensive enough to prepare them for smooth transition into adulthood and employment. From the above indicatives and discussions it can be noted that we do not have a supervised, clear cut and planned curricula to be followed by various settings offering special needs education. This is in line with the claims made by Mkandhla and Mataruse (2002) as well as Mpofu 2001.The question which always come to mind when faced with such a situation is that of legislation. Would the situation not be different if we had specific special needs legislation in place which spells out the who, how and when of the curricula?

From the demographic characteristics of respondents, interesting trends can be observed. About half of the teachers were highly qualified with degrees in special education and about $20 \%$ had diplomas in special education. Only 30.8\% had general teacher qualifications. While the Chakanyuka et al report (2009) showed critical shortage of specialist teachers, the current study indicated the opposite. It has to be observed however that the difference is as a result of the differences in the research field. The current study mainly focused on established special education institutions while the former concentrated on the mainstream. In this vein the current study concurs with the Chakanyuka et al (op.cit) report because the $30.8 \%$ of the teachers who had general teacher qualifications were those in special classes and resource units. Considering the fact that the current trend in special education is towards inclusive education there is a critical shortage of qualified specialist teachers in the mainstream school. As such the current study showed a strong human capital as a result of the institutions studied. These mainly sought the service of specialist teachers. The research results have also indicated that $67 \%$ of school heads face problems in recruiting specialist teachers to their schools citing non availability, refusal by some to take special classes, centralized recruitment systems and poor incentives. In situations like this it is imperative to provide support services to the teachers. As indicated in chapter two, such support can be provided by information gained from specialist or peripatetic staff and in-service training among others. If the philosophy of inclusive education is to be successful there is need for strong intervention regarding teacher training and conditions of service for specialist teachers.

\section{Recommendations}

The following recommendations are made basing on the thematic areas studied.

\subsubsection{The general strengths of specialist teachers}

- With current trends towards inclusive education it is recommended that all teachers colleges and universities include special education in their curriculum and make it a compulsory component.

- Teaching learners with disabilities presents huge challenges. A retention allowance be paid to all qualified teachers of learners with disabilities and other special needs.

- That the members of the multidisciplinary team that assist learners with disabilities be stationed in each cluster for a start and later on move to school level. These may initially include a counsellor, psychologist, nurse, rehabilitation technician, occupational therapist and physiotherapist. This will help teachers focus on their core business of teaching rather than the current trend where specialist teachers are jacks of all.

- That all school heads continually undergo in-service training in special education to increase their appreciation of learners with disabilities

- That the deployment of specialist teachers be given special treatment taking into consideration that not all schools are yet at the stage of providing special education.

- That specialist teachers be recruited at school level rather than at district or provincial levels 


\subsubsection{Parental involvement}

\section{It is recommended that}

- Parents of children with disabilities be empowered to actively participate in valued activities such as the design of Individual Education Programmes. The empowerment must be supported by legislation or policies.

- Schools sign contracts with parents in which the later undertook to participate in all the outlined activities.

\subsubsection{Curricula}

- The government must design a well structured curricula for learners with disabilities in general with disability specific provisions to allow uniformity in provision and supervision of special needs education

- That a clear cut transitional policy be instituted which specifies the paths to be followed by children with disabilities in school to enable them to move swiftly into adulthood and employment. The transitional policy must be disability specific.

- Stakeholders, especially employers be consulted from time to time such to provide feedback on the job performance of disabled people which is in turn used for curricula modification.

- Support services be put in place for employed school leavers with disabilities.

- Dictionaries with technical signs be put in place for the teaching and learning of subjects such as science, geography, computers and others.

\section{References}

[1]. Addison, J. (1986). A Historical Survey of Facilities for Handicapped People in Zimbabwe. Harare: S.C.F.

[2]. Barnatt, S. N., \& Kabzems, V. (1992). Zimbabwean teachers' attitudes towards the integration of pupils with disabilities into regular classrooms. International Journal of Disability, Developmentand Education, 39, 135-146.

[3]. Chakanyuka, S., Chung, F. K. and Stevenson, T. (2009) The Rapid Assessments of Primary and Secondary Schools. Harare: National Education Advisory Board.

[4]. Cohen, A. and Cohen, L. (1986). Special Educational Needs in the Ordinary School. London: Harper Education Series.

[5]. Disabled Persons Act. (1996). Harare, Zimbabwe: Government Printers.

[6]. Education Act. (1996). Harare, Zimbabwe: Government Printers.

[7]. Education Secretary's Policy Circular Number 36. (1990). Harare, Zimbabwe.

[8]. Education Secretary's Policy Circular Number 12. (1987). Harare, Zimbabwe:

[9]. Maunganidze, L., \& Kasayira, J. M. (2002). Educational integration of children with disabilities in schools in the Midlands region of Zimbabwe. The Zimbabwe Bulletin of Teacher Education, 11(1), 72-82.

[10]. Mnkandla, M., \& Mataruse, K. (2002). The impact of inclusion policy on school psychology in Zimbabwe. Educational and Child Psychology, 19, 12-23.

[11]. Mpofu, E. (1999). Social acceptance of early adolescents with physical disabilities. Unpublished doctoral dissertation, University of Wisconsin-Madison

[12]. Mpofu, E. (2001). Learning disabilities: Theories, practices and applications in the Zimbabwean context. In M. Peresuh \& T. Nhundu (Eds.), Foundations of Education in Africa Harare, Zimbabwe: College Press.

[13]. Mpofu, E. (2000a). Educational considerations for students who are mentally challenged. Harare, Zimbabwe: Zimbabwe Open University.

[14]. Mpofu, E. (2004). Learning through inclusive education: Practices with students with disabilities in sub-Saharan Africa. In C. de la Rey, L. Schwartz, \& N. Duncan (Eds.), Psychology: An introduction (pp. 361-371). Cape Town : Oxford University Press.

[15]. The Salamanca Statement and Framework for Action on Special Needs Education: World Conference on Special Needs Education. Salamanca, Spain, 7-10 June 1994.

[16]. United Nations Convention on the Rights of the Child. Adopted by the General Assembly of the United Nations on 20 November 1989. 